\title{
Antiproliferative Illudalane Sesquiterpenes from the Marine Sediment Ascomycete Aspergillus oryzae
}

\author{
Raha Orfali ${ }^{1, *}$, Shagufta Perveen ${ }^{1, * \mathbb{D}}$, Muhammad Farooq Khan ${ }^{2} \mathbb{D}$, Atallah F. Ahmed ${ }^{1,3} \mathbb{D}_{\text {, }}$ \\ Mohammad A. Wadaan ${ }^{2}$, Areej Mohammad Al-Taweel ${ }^{1}$, Ali S. Alqahtani ${ }^{1,4}{ }^{\mathbb{D}}$, Fahd A. Nasr ${ }^{4} \mathbb{D}$, Sobia Tabassum ${ }^{5}$, \\ Paolo Luciano ${ }^{6}$, Giuseppina Chianese ${ }^{6}\left(\mathbb{D}\right.$, Jyh-Horng Sheu ${ }^{7,8}$ and Orazio Taglialatela-Scafati ${ }^{6, *(D)}$
}

1 Department of Pharmacognosy, College of Pharmacy, King Saud University, P.O. Box 2457, Riyadh 11451, Saudi Arabia; afahmed@ksu.edu.sa (A.F.A.); amaltaweel@ksu.edu.sa (A.M.A.-T.); alalqahtani@ksu.edu.sa (A.S.A.)

2 Bio-Products Research Chair, Department of Zoology, College of Science, King Saud University, P.O. Box 2455, Riyadh 11451, Saudi Arabia; fmuhammad@ksu.edu.sa (M.F.K.); wadaan@ksu.edu.sa (M.A.W.)

3 Department of Pharmacognosy, Faculty of Pharmacy, Mansoura University, Mansoura 35516, Egypt

4 Medicinal, Aromatic and Poisonous Plants Research Center, College of Pharmacy, King Saud University, P.O. Box 2455, Riyadh 11451, Saudi Arabia; fnasr@ksu.edu.sa

5 Interdisciplinary Research Centre in Biomedical Materials (IRCBM), Lahore Campus, COMSATS University Islamabad, Islamabad 44000, Pakistan; sobiatabassum@cuilahore.edu.pk

check for updates

Citation: Orfali, R.; Perveen, S.; Khan, M.F.; Ahmed, A.F.; Wadaan, M.A.; Al-Taweel, A.M.; Alqahtani, A.S.; Nasr, F.A.; Tabassum, S.; Luciano, P.; et al. Antiproliferative Illudalane Sesquiterpenes from the Marine Sediment Ascomycete Aspergillus oryzae. Mar. Drugs 2021, 19, 333. https://doi.org/10.3390/ md19060333

\section{Academic Editors:}

RuAngelie Edrada-Ebel,

Chang-Yun Wang and Bin-Gui Wang

Received: 20 May 2021

Accepted: 7 June 2021

Published: 10 June 2021

Publisher's Note: MDPI stays neutral with regard to jurisdictional claims in published maps and institutional affiliations.

Copyright: (c) 2021 by the authors. Licensee MDPI, Basel, Switzerland. This article is an open access article distributed under the terms and conditions of the Creative Commons Attribution (CC BY) license (https:// creativecommons.org/licenses/by/ $4.0 /)$.
6 Department of Pharmacy, School of Medicine and Surgery, University of Naples Federico II, Via Montesano 49, 80131 Naples, Italy; pluciano@unina.it (P.L.); g.chianese@unina.it (G.C.)

7 Department of Marine Biotechnology and Resources, National Sun Yat-sen University, Kaohsiung 80424, Taiwan; sheu@mail.nsysu.edu.tw

8 Department of Medical Research, China Medical University Hospital, China Medical University, Taichung 40447, Taiwan

* Correspondence: rorfali@ksu.edu.sa (R.O.); shakhan@ksu.edu.sa (S.P.); scatagli@unina.it (O.T.-S.)

Abstract: The new asperorlactone (1), along with the known illudalane sesquiterpene echinolactone $\mathrm{D}$ (2), two known pyrones, 4-(hydroxymethyl)-5-hydroxy-2H-pyran-2-one (3) and its acetate 4, and 4-hydroxybenzaldehyde (5), were isolated from a culture of Aspergillus oryzae, collected from Red Sea marine sediments. The structure of asperorlactone (1) was elucidated by HR-ESIMS, 1D, and 2D NMR, and a comparison between experimental and DFT calculated electronic circular dichroism (ECD) spectra. This is the first report of illudalane sesquiterpenoids from Aspergillus fungi and, more in general, from ascomycetes. Asperorlactone (1) exhibited antiproliferative activity against human lung, liver, and breast carcinoma cell lines, with $\mathrm{IC}_{50}$ values $<100 \mu \mathrm{M}$. All the isolated compounds were also evaluated for their toxicity using the zebrafish embryo model.

Keywords: Aspergillus oryzae; marine fungus; illudalane sesquiterpenes; antiproliferative activity; zebrafish toxicity

\section{Introduction}

The marine environment is an unsurpassed casket of chemodiversity and a prolific source of biologically active compounds with potential medicinal applications [1]. In the last 50 years, scientists all over the world have dedicated their efforts to uncover the potential of marine metabolites, succeeding in the isolation of thousands of natural products with peculiar architectures and interesting bioactivities [2]. As per April 2021, the marine pharmacology arsenal [3] includes 15 approved drugs (mainly for cancer treatment), seven compounds in phase I, 12 compounds in phase II, and 5 compounds in phase III clinical trials, the latter including plitidepsin, recently proposed for COVID-19 symptomatic treatment $[4,5]$. Sponges and tunicates are undoubtedly the most intensely studied marine organisms, but it is now clear that marine microbes, isolated from sediments or from symbiotic plants or invertebrates, constitute a rich source for secondary metabolites. In this 
context, although terrestrial fungi are more explored, in comparison to their marine counterparts, a surprising number of structurally unique compounds have been isolated from fungi living in marine habitats [6]. The peculiar properties of the marine environment with regard to nutrients, temperature, and competition, are likely crucial factors in improving the ability of marine fungi to elaborate compounds with promising bioactivities, especially suited for antibiotic and anticancer applications [7].

The genus Aspergillus is one of the most abundant among marine ascomycetes, characterized by high salt tolerance, fast growth rate, and the capacity to adapt to diverse habitats. Marine Aspergillus fungi produce a wide range of secondary metabolites belonging to different classes and are endowed with a broad array of biological activities of industrial and pharmaceutical interest $[8,9]$. As a part of our ongoing research activity aimed at the isolation of bioactive compounds from terrestrial and marine fungi [10-13], A. oryzae samples obtained from the sediments of the Red Sea, along the coasts of Saudi Arabia, were chemically investigated. This study resulted in the isolation of two illudalane sesquiterpenes, the new asperorlactone (1) and the known echinolactone D (2), along with two rare pyrone derivatives (3-4) and 4-hydroxybenzaldehyde (5). These compounds were evaluated for their antiproliferative activity against three human carcinomas (lung, liver, and breast) cell lines. Chemotherapeutics used in cancer treatment are often characterized by marked toxic effects on normal cells. Less than $2 \%$ of compounds emerging from in vitro drug screening could enter clinical trials since the majority of the newly developed leads fail in preclinical testing due to their toxicity in experimental animal models [14]. In vitro drug screening methods are prevalently used in order to characterize the bioactivity and the toxicity of new compounds, while testing their safety in suitable animal models prior to clinical trials would save time and money. Since a high throughput screening approach is not feasible in higher animals, zebrafish constitute a valid option for preclinical testing and have shown quite reproducible results. It is predicted that, following further development of technologies, zebrafish will play a key role in speeding up the emergence of precision medicine $[15,16]$. On these bases, the isolated compounds 1-5 have been tested for their zebrafish animal toxicity, and results are reported herein.

\section{Results and Discussion}

\subsection{Extraction and Structural Identification}

A. oryzae samples were isolated from the Red Sea sediment collected at a depth of$50 \mathrm{~m}$ off Jeddah, Saudi Arabia. Fermentation of the fungus on solid rice medium and extraction with EtOAc afforded a brownish residue, which was chromatographed by using silica gel and RP-18 column chromatography, affording one new (1) and four known (2-5) compounds (Figure 1).<smiles>[X]C1(C)C=Cc2cc3c(c(C)c2C1)[C@@H](O)COC3=O</smiles><smiles>[R]Cc1cc(=O)occ1O</smiles>

$3 \mathrm{R}=\mathrm{H}$

$4 \mathrm{R}=\mathrm{Ac}$<smiles>Cc1c2c(cc3c1CC[C@@]3(C)CO)C(=O)OCC2</smiles><smiles>O=Cc1ccc(O)cc1</smiles>

5

Figure 1. Chemical structures of metabolites isolated from A. oryzae. 
The known compounds were identified as echinolactone D (2) [17], 4-(hydroxymethyl)5-hydroxy-2H-pyran-2-one (3) [18], (5-hydroxy-2-oxo-2H-pyran-4-yl)methyl acetate (4) [16], and 4-hydroxybenzaldehyde (5), by a comparison of their spectroscopic data with those reported in the literature. The illudalane echinolactone D (2) had been isolated before from mycelia of the fungus Echinodontium japonicum [17] and from the wood decomposing fungus Granulobasidium vellereum [19], and therefore, this is its first report from a marine source. Compound 3 is a rare isomeric analog of kojic acid for which only three reports were present in the literature, all from Aspergillus fungi (marine A. flavus [18], terrestrial A. niger [20], and freshwater A. austroafricanus [21]).

Asperorlactone (1) was isolated as a colorless oil with molecular formula $\mathrm{C}_{15} \mathrm{H}_{18} \mathrm{O}_{3}$, determined by HR-ESIMS. The ${ }^{13} \mathrm{C}$ NMR and DEPT spectra of $\mathbf{1}$ (Table 1 ) showed the presence of one lactone carbonyl $\left(\delta_{C} 166.5\right)$, one aromatic methine $\left(\delta_{C} 123.1\right)$, one oxymethine $\left(\delta_{C} 60.8\right)$, one $\mathrm{sp}^{3}\left(\delta_{C} 39.3\right)$ and five $\mathrm{sp}^{2}\left(\delta_{C} 122.7,132.2,136.2,144.3,150.1\right)$ nonprotonated carbons, three $\mathrm{sp}^{3}$ methylenes $\left(\delta_{C} 46.5,47.1,72.7\right.$, the latter O-bearing), and three methyl groups $\left(\delta_{C} 13.1,27.5 \times 2\right)$. On the basis of these data, the seven unsaturation equivalents required by the molecular formula of $\mathbf{1}$ could be accommodated by the presence of a benzene ring and of two additional rings, including a lactone.

The ${ }^{1} \mathrm{H}$ NMR spectrum of $\mathbf{1}$ (Table 1 ) showed only one aromatic methine signal $\left(\delta_{\mathrm{H}} 7.75\right)$, two methyl singlets $\left(\delta_{\mathrm{H}} 1.19 \times 2\right)$, an arylmethyl at $\delta_{\mathrm{H}} 2.37(\mathrm{~s}, 3 \mathrm{H})$, and two pairs of methylenes around $\delta_{\mathrm{H}} 2.80-2.83$. The single-spin system of $\mathbf{1}$ included a diastereoptopic hydroxymethylene $\left(\delta_{\mathrm{H}} 4.52\right.$ and 4.63$)$, and an oxymethine signal $\left(\delta_{\mathrm{H}} 4.95\right)$. Having associated all these proton signals to those of the directly linked carbons with the 2D NMR HSQC experiment, the illudalane type sesquiterpenes skeleton of compound 1 could be established by following the correlation network of the 2D NMR HMBC spectrum (Figure 2) (see Supplementary Materials).

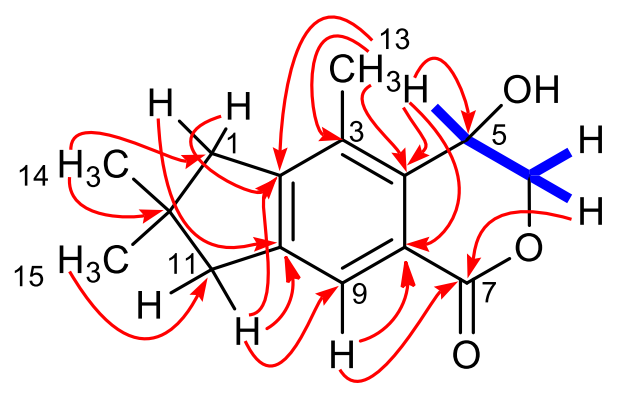

Figure 2. COSY (blue) and key HMBC (red arrows) correlations for compound 1.

Table 1. ${ }^{1} \mathrm{H}(700 \mathrm{MHz})$ and ${ }^{13} \mathrm{C}(175 \mathrm{MHz}) \mathrm{NMR}$ data for asperorlactone (1) in $\mathrm{CD}_{3} \mathrm{OD}$.

\begin{tabular}{ccc}
\hline Positions & $\delta_{\mathbf{H}}$ (Mult., $\boldsymbol{J}$ in Hz) & $\delta_{\mathbf{C}, \text { Type }}$ \\
\hline $1 \mathrm{a}$ & 2.83 (overlapped) & $46.5, \mathrm{CH}_{2}$ \\
$1 \mathrm{~b}$ & $2.81(\mathrm{~d}, 17.5)$ & \\
2 & - & $150.1, \mathrm{C}$ \\
3 & - & $132.2, \mathrm{C}$ \\
4 & - & $136.2, \mathrm{C}$ \\
5 & $4.95(\mathrm{dd}, 1.0,2.1)$ & $60.8, \mathrm{CH}$ \\
6 & $4.63(\mathrm{dd}, 1.0,12.0)$ & $72.7, \mathrm{CH}_{2}$ \\
7 & $-52(\mathrm{dd}, 2.1,12.0)$ & $166.5, \mathrm{C}$ \\
8 & - & $122.7, \mathrm{C}$ \\
9 & $7.75(\mathrm{~s})$ & $123.1, \mathrm{CH}$ \\
10 & - & $144.3, \mathrm{C}$ \\
11 & $2.82($ overlapped $)$ & $47.1, \mathrm{CH}_{2}$ \\
12 & - & $39.3, \mathrm{C}$ \\
13 & $2.37(\mathrm{~s})$ & $13.1, \mathrm{CH}_{3}$ \\
\hline
\end{tabular}


Table 1. Cont.

\begin{tabular}{ccc}
\hline Positions & $\delta_{\mathbf{H}}($ Mult., $\boldsymbol{J}$ in Hz) & $\delta_{\mathbf{C}}$, Type \\
\hline 14 & $1.19(\mathrm{~s})$ & $27.5, \mathrm{CH}_{3}$ \\
15 & $1.19(\mathrm{~s})$ & $27.5, \mathrm{CH}_{3}$ \\
\hline
\end{tabular}

In particular, correlations of $\mathrm{H}-9$ with $\mathrm{C}-8$ and the lactone $\mathrm{C}-7$, of $\mathrm{H}-5$ with $\mathrm{C}-4$ and $\mathrm{C}-8$, and of $\mathrm{H}_{2}-6$ with $\mathrm{C}-7$ defined the structure of the hydroxyisochroman-1-one moiety of asperorlactone. The structure of the condensed dimethylated five-membered ring was deduced from the correlation of $\mathrm{H}_{3}-14 / \mathrm{H}_{3}-15$ with $\mathrm{C}-1, \mathrm{C}-11$, and $\mathrm{C}-12$ and of $\mathrm{H}_{2}-1$ and $\mathrm{H}_{2}-11$ with $\mathrm{C}-2$ and $\mathrm{C}-10$. Finally, the remaining methyl group was attached at $\mathrm{C}-3$, following its correlations with C-2, C-3, and C-4.

Asperorlactone (1) is an optically active compound $\left([\alpha]_{D}^{23}-19.8\right)$ with a single stereocenter (C-5). We first tried to define the absolute configuration of $\mathbf{1}$ by employing the modified Mosher's method [22]; however, all the attempts to obtain the formation of the MTPA esters from the corresponding chloride failed. Most likely, the reaction of the bulky MTPA group with the hydroxyl group at C-5 was hindered by the methyl group present on the condensed aromatic ring. Therefore, we decided to rely on computational calculations, reasoning that comparison between experimental and quantum mechanically calculated ECD spectrum could provide an unambiguous indication on the absolute configuration of $\mathbf{1}$.

The structure of 1 was subjected to a geometry and energy optimization using DFT with the mPW1PW91/6-311+G $(\mathrm{d}, \mathrm{p})$ functional and basis set combination using the Gaussian 09 software. The reasonably populated conformations, their relative energy, and the equilibrium room-temperature Boltzmann populations are reported in Figure 3. The two major conformers $\mathbf{1 a}$ and $\mathbf{1 b}$, accounting for $99.5 \%$ of the total population, differ almost exclusively for the pseudorotation of the five-membered ring.

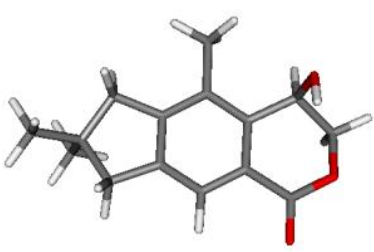

Conformer 1a Population $52.8 \%$

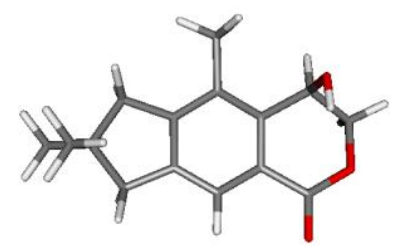

Conformer $\mathbf{1 b}$ $\Delta \mathrm{G}=0.40 \mathrm{Kcal} / \mathrm{mo}$ Population $46.7 \%$

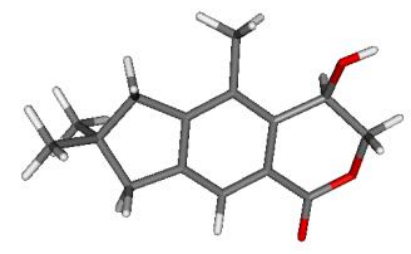

Conformer 1c $\Delta \mathrm{G}=11.30 \mathrm{Kcal} / \mathrm{mol}$ Population $0.5 \%$

Figure 3. The reasonably populated conformers $\mathbf{1 a}-\mathbf{1 c}$ of $\mathbf{1}$ and their calculated Boltzmann population.

TDDFT calculations were run using the functional CAM-B3LYP and the basis sets 6-31G $(\mathrm{d}, \mathrm{p})$ including at least 30 excited states in all cases, and using IEF-PCM for MeOH. The rotatory strength values were summed after a Boltzmann statistical weighting, and $\Delta \varepsilon$ values were calculated by forming sums of Gaussian functions centered at the wavelengths of the respective electronic transitions and multiplied by the corresponding rotatory strengths. Thus, the ECD spectra for $R \mathbf{- 1}$ and $S-\mathbf{1}$ were obtained (Figure 4). The extensive similarity of the first with the experimental ECD spectrum allowed us a confident assignment of the absolute configuration of asperorlactone as $5 R$.

The isolation of asperorlactone (1), as well as of the related echinolactone D (2), is of great relevance because, to our knowledge, this is the first report of illudalane-type sesquiterpenes from an ascomycete (A. oryzae), since this class of metabolites has, until now, been found exclusively in basidiomycetes. 


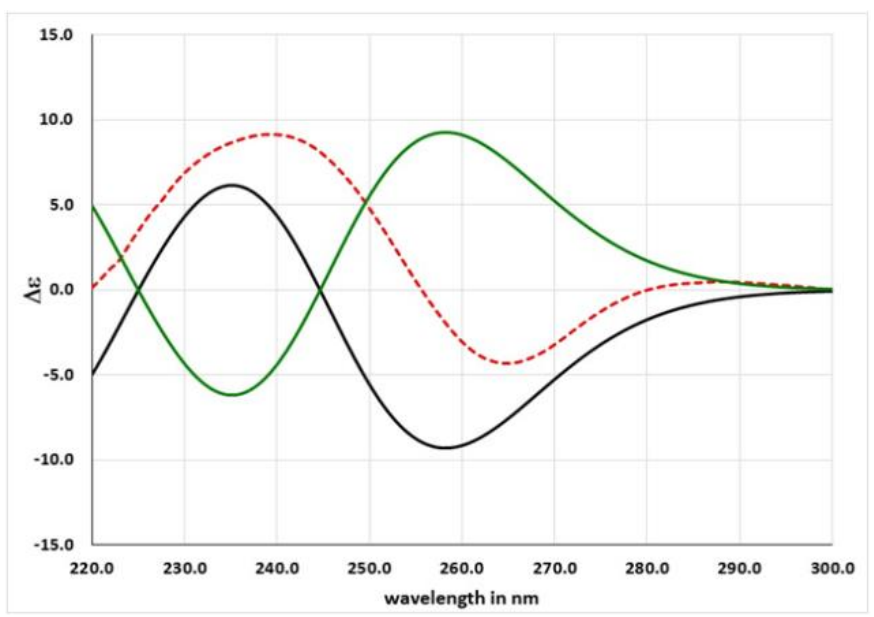

Figure 4. Experimental ECD curve of asperorlactone (red) and calculated ECD curves for R-1 (black) and $S \mathbf{- 1}$ (green).

It has been reported that illudalanes derive biosynthetically from a humulene precursor that, upon cyclization, would generate a protoilludane that finally would rearrange to form the illudalane derivative [23]. In the light of this hypothesis, a possible biosynthesis of asperorlactone is reported in Figure 5, where illudol [24] is a key intermediate that could afford 1 by dehydration, oxidation, and four-membered ring opening.

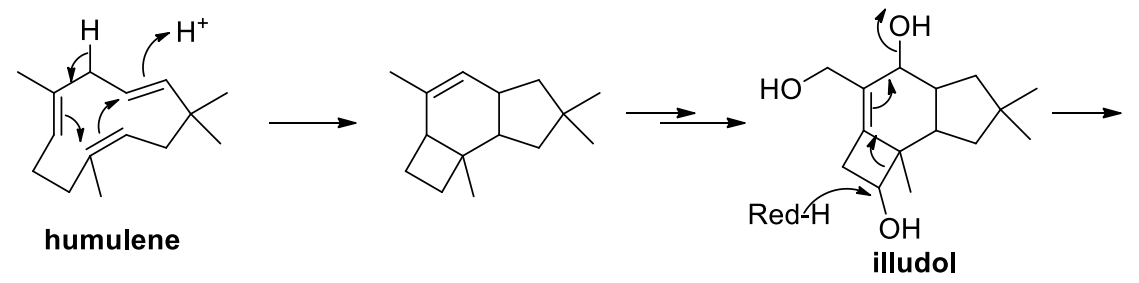

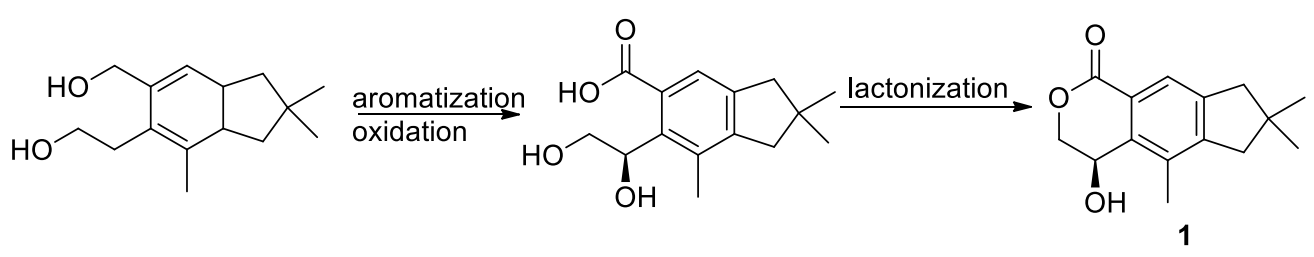

Figure 5. Postulated biosynthesis of asperorlactone (1).

\subsection{Pharmacological and Toxicological Evaluation of the Isolated Compounds}

Illudalane sesquiterpenes, obtained from different sources, have been reported to possess several biological properties, with a special focus on anticancer activities $[25,26]$. This prompted us to evaluate the antiproliferative activity of compounds 1-5 against three human cancer cell lines, namely, lung carcinoma (A549), liver carcinoma (HepG2), and breast carcinoma (MCF7). The obtained $\mathrm{IC}_{50}$ values are presented in Table 2. Compounds 1-5 generally showed moderate antiproliferative activity against all tested cell lines, invariably with higher potency against lung carcinoma, as compared to liver or breast carcinoma. As shown in Table 1, asperorlactone (1) and compound $\mathbf{2}$ were the most potent compounds against three cancer cell lines, with the single exception of the activity of 5 against the MCF-7 cell line. Additionally, interesting is the comparison between compounds $\mathbf{3}$ and $\mathbf{4}$, evidencing that acetylation improves the activity against A549 and HepG2. 
Table 2. Antiproliferative activity of compounds 1-5 against three human cancer cell lines.

\begin{tabular}{cccc}
\hline Compound & \multicolumn{2}{c}{ IC $_{\mathbf{5 0}}(\boldsymbol{\mu M})$ for the Different Carcinoma Cell Lines } \\
\hline $\mathbf{1}$ & $72.7 \pm 1.1$ & HepG2 (Liver) & MCF-7 (Breast) \\
$\mathbf{2}$ & $55.7 \pm 2.5$ & $86.6 \pm 3.2$ & $106.5 \pm 4.2$ \\
$\mathbf{3}$ & $208.5 \pm 6.8$ & $148.4 \pm 5.6$ & $128.0 \pm 2.8$ \\
$\mathbf{4}$ & $89.4 \pm 2.3$ & $220.4 \pm 3.6$ & $225.4 \pm 5.1$ \\
$\mathbf{5}$ & $97.5 \pm 2.6$ & $126.8 \pm 6.4$ & $170.7 \pm 4.5$ \\
Doxorubicin & $2.1 \pm 0.08$ & $242.6 \pm 6.4$ & $158.2 \pm 5.5$ \\
\hline
\end{tabular}

As anticipated, screening in zebrafish embryos provides an excellent environment in which the toxicity of a compound on noncancer cells and systems could be predicted. Thus, the zebrafish embryos model was used to evaluate the animal toxicity of compounds 1-5 (Figure 6). The $\mathrm{LC}_{50}$ values (the concentration required to kill $50 \%$ of embryos) of all the tested compounds were higher than the $1 \mathrm{mg} / \mathrm{mL}$ range, indicating their safety on noncancer cells and selectivity indices $>50$. The zebrafish embryos that were treated with compounds $\mathbf{2}, \mathbf{3}$, and $\mathbf{5}$ did not exhibit any observable toxicity, and they developed normally up to 3 days post treatment. On the other hand, compound 4, for which the initial development and growth of zebrafish embryos was normal, induced the death of $100 \%$ of treated embryos after $24 \mathrm{~h}$ post treatment. The zebrafish embryos that were treated with more than $200 \mu \mathrm{M}$ compound $\mathbf{1}$ (higher than $\mathrm{IC}_{50}$ ) developed normally; however, the embryos exhibited cardiac toxicity (cardiac edema and cardiac hypertrophy, black arrow in Figure 6) after 2 days post treatment.

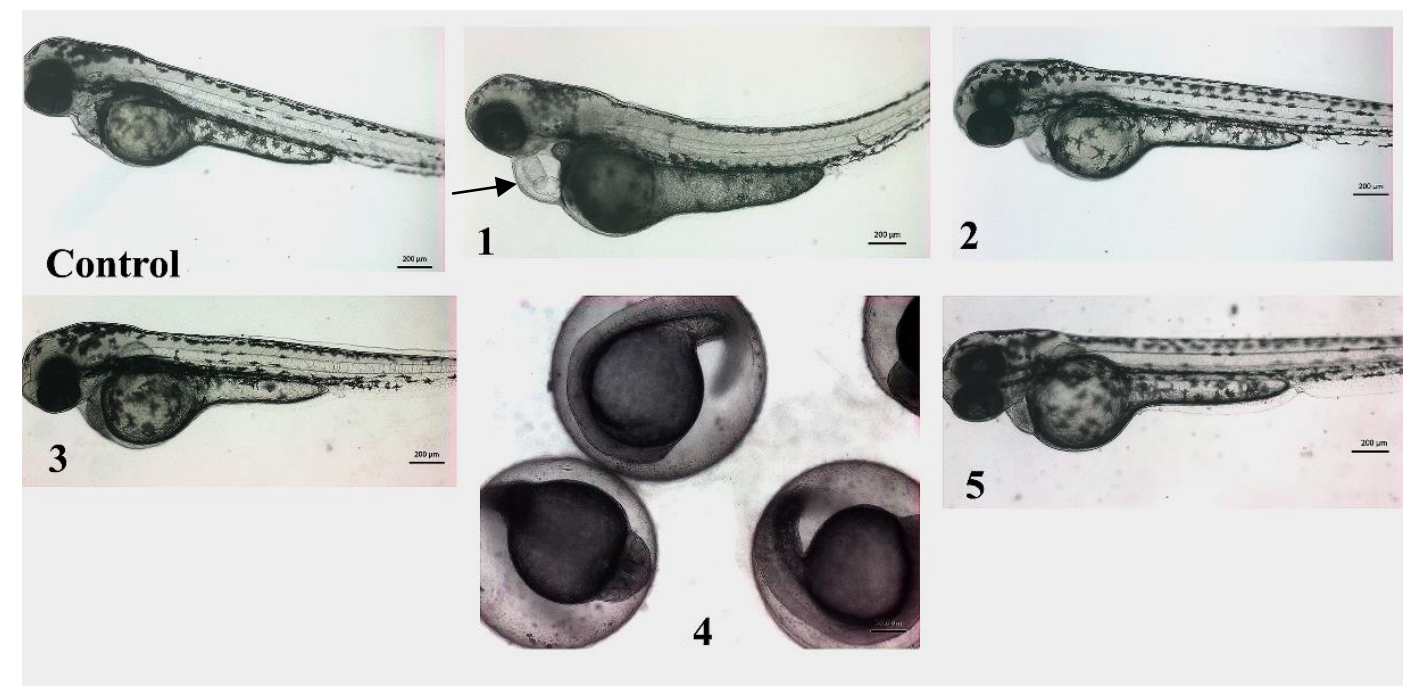

Figure 6. In vivo screening of compounds 1-5 in zebrafish embryos. Representative micrograph of embryos at 3 days poster fertilization, which were treated with compounds $\mathbf{1}-\mathbf{5}$. The zebrafish embryos treated with compounds 2, 3, and 5 developed normally, and there were no obvious differences in morphology and growth between control and treated embryos. The zebrafish embryos treated with $>200 \mu \mathrm{M}$ of $\mathbf{1}$, however, had cardiac edema and cardiac hypertrophy (black arrow). The zebrafish embryos treated with compound 4 developed normally but were found dead on day 2 . All the images are in same magnification, scale is $200 \mu \mathrm{m}$.

\section{Materials and Methods}

\subsection{Fungal Material}

Aspergillus oryzae was isolated from the marine sediment collected at $-50 \mathrm{~m}$ off Jeddah, Red Sea, Saudi Arabia, in October 2018. The fungal identification was conducted by DNA amplification and sequencing of the internal transcribed spacer region (GenBank accession 
No. MH608347) followed by a subsequent BLAST search in NCBI according to the protocol described before [27]. The specimen of the fungal strain was deep-frozen and deposited at the authors' lab (R.O., S.P.).

\subsection{Fermentation, Extraction, and Isolation}

A. oryzae was cultivated in 20 Erlenmeyer flasks on solid rice medium containing (100 g rice, $3.5 \mathrm{~g}$ sea salt, and $110 \mathrm{~mL}$ of demineralized water). After autoclaving at $121^{\circ} \mathrm{C}$ for $20 \mathrm{~min}$ and then cooling to room temperature, each flask was inoculated and then incubated at $20^{\circ} \mathrm{C}$ under static conditions. After four weeks, $500 \mathrm{~mL}$ EtOAc was added to each flask to stop the fermentation and extract. The total extract was collected after the flasks had been shaken at $150 \mathrm{rpm}$ for $8 \mathrm{~h}$ on a laboratory shaker. The obtained crude extract after evaporation of the EtOAc $(7 \mathrm{~g})$ was then partitioned between $n$-hexane and $\mathrm{MeOH}$. The polar phase was then subjected to Sephadex LH-20 column $(100 \times 2.5 \mathrm{~cm})$ using $100 \%$ methanol as an eluting solvent. Similar fractions were combined with each other according to TLC readings and further purified by semipreparative HPLC using gradient system $\mathrm{MeOH}-\mathrm{H}_{2} \mathrm{O}$ from 40:60 to 70:30 in $30 \mathrm{~min}$ to afford $\mathbf{1}(3.5 \mathrm{mg}), \mathbf{2}(5.0 \mathrm{mg})$, 3 (7.0 mg), 4 (5.0 mg), and 5 (2.6 mg).

Asperorlactone (1). Colorless oil; $[\alpha]_{\mathrm{D}}^{23}-19.8($ c 0.6, $\mathrm{MeOH}) ; \mathrm{UV} \lambda_{\max }(\mathrm{MeOH}) \mathrm{nm}(\log \varepsilon)$ : 230 (4.6); ECD $\lambda_{\max }(\mathrm{MeOH}) \mathrm{nm}(\Delta \varepsilon): 238(+9.6), 265(-4.8) ;{ }^{1} \mathrm{H} \mathrm{NMR}\left(700 \mathrm{MHz}, \mathrm{CD}_{3} \mathrm{OD}\right)$, and ${ }^{13} \mathrm{C}$ NMR (175 MHz, CD ${ }_{3} \mathrm{OD}$ ); see Table 1; ESIMS m/z $269.1150[\mathrm{M}+\mathrm{Na}]^{+}$(calc. for $\mathrm{C}_{15} \mathrm{H}_{18} \mathrm{O}_{3} \mathrm{Na} m / z$ 269.1154).

\subsection{Computational Calculations}

A preliminary conformational search on each stereoisomer was performed by Simulated Annealing in the INSIGHT II package. The $\mathrm{MeOH}$ solution phases were mimicked through the value of the corresponding dielectric constant. Using the steepest descent followed by quasi-Newton-Raphson method (VA09A) the conformational energy was minimized. Restrained simulations were carried out for 500 ps using the CVFF force field as implemented in Discovery software (Version 4.0 Accelrys, San Diego, USA). The simulation started at $1000 \mathrm{~K}$, and then the temperature was decreased stepwise to $300 \mathrm{~K}$. The final step was again the energy minimization, performed in order to refine the conformers obtained, using the steepest descent and the quasi-Newton-Raphson (VA09A) algorithms successively. Both dynamic and mechanic calculations were carried out by using $1(\mathrm{kcal} / \mathrm{mol}) / \mathrm{A}^{\circ}$ 2 flat well distance restraints. In total, 100 structures were generated. TDDFT calculations were run using the functional CAM-B3LYP and the basis sets 6-31G $(\mathrm{d}, \mathrm{p})$ including at least 30 excited states in all cases, and using IEF-PCM for $\mathrm{MeOH}$. The rotatory strength values were summed after a Boltzmann statistical weighting, and $\Delta \varepsilon$ values were calculated by forming sums of Gaussian functions centered at the wavelengths of the respective electronic transitions and multiplied by the corresponding rotatory strengths. The ECD spectra that were obtained were UV-corrected and compared with the experimental ones.

\subsection{In Vitro Antiproliferative Activity}

The antiproliferative activity of compounds was measured using MTT (3-(4, 5-dimethylthiazol-2-yl)-2,5-diphenyltetrazolium bromide) assay. A549 (lung), HepG2 (liver), and MCF-7 (breast) cancer cells were purchased from the American Type Cell Collection (ATCC, Manassas, VA, USA). The cells were seeded at $5 \times 10^{4}$ cells/well (in $100 \mu \mathrm{L}$ of DMEM) in 96-well microplates. After $24 \mathrm{~h}$ incubation at $37^{\circ} \mathrm{C}$, serial dilution $(15-250 \mu \mathrm{M})$ of each compound was added and incubated for $48 \mathrm{~h}$. Thereafter, $10 \mu \mathrm{L}$ of the MTT solution $(5 \mathrm{mg} / \mathrm{mL})$ was added to each well. After $4 \mathrm{~h}$ incubation with the MTT solution, a volume of $100 \mu \mathrm{L}$ of acidified isopropanol was added to solubilize the formazan product and incubated on a shaker for a further $10 \mathrm{~min}$. Reduced MTT was assayed at $570 \mathrm{~nm}$ using a microplate reader (BioTek, Winoosky, VT, USA). Control groups received the same amount of DMSO $(0.1 \%)$, untreated cells were used as a negative control, whereas cells treated with doxorubicin were used as a positive control. The $\mathrm{IC}_{50}$ (concentration that caused more 
than $50 \%$ inhibition of proliferation) was calculated from a dose-dependent curve. The cell viability percent was calculated $=$ mean absorbance of treated sample $/$ mean absorbance of control $\times 100$.

\subsection{Zebrafish Toxicity Screening}

Wild-type zebrafish strain AB/Tuebingen TAB-14(AB/TuebingenTAB-14) (Catalog ID: ZL1438) were obtained from zebrafish international resource center and grown in an animal facility at the Department of Zoology, King Saud University, Riyadh, Kingdom of Saudi Arabia. The fish were maintained and bred following guidelines of the Institutional Animal Care and Use Committee (ICUAC) and zebrafish book. The fertilized embryos were obtained by natural pairwise breeding of adult fish. The fertilized embryos were sorted, dead embryos were removed, and synchronous stage embryos were used for screening.

A stock solution of $25 \mathrm{mM}$ was made by dissolving the compounds in molecular biology grade DMSO (Sigma Aldrich, St. Louis, MI, USA). Zebrafish embryos were exposed to serial dilution $(1,5,15,45,150$, and $300 \mu \mathrm{M})$ of each compound. The embryos were remained exposed to the compounds for 3 days, and the embryos medium containing the compounds were changed every day. The response of the embryos toward mortality, and embryonic toxicity (teratogenicity) was monitored once after $12 \mathrm{~h}$ and then after every $24 \mathrm{~h}$ until the end of the experiment. The experiment was repeated at least three times (triplicate biological repeats) by using a new batch of embryos every time. $\mathrm{LC}_{50}$ for zebrafish embryonic toxicity was calculated by using an updated Probit analysis by Finney method [28].

\section{Conclusions}

Samples of A. oryzae, obtained from the Red Sea sediments collected off Jeddah, Saudi Arabia, afforded the first illudalane sesquiterpenoids isolated from an ascomycete, including the new asperorlactone (1), characterized by hydroxylation of the lactone ring. Elucidation of the structure and absolute configuration of this compound needed application of ESIMS and NMR spectral analyses and computational calculations of ECD spectra. The isolated compounds showed moderate antiproliferative activity against three human carcinoma cell lines (lung, liver, and breast). The zebrafish embryo model was used to evaluate the animal toxicity of compounds and selected echinolactone D (2) and the rare pyrone 3 as targets worthy of further investigation.

Supplementary Materials: The following are available online at https:/ /www.mdpi.com/article/ 10.3390/md19060333/s1, Figures S1-S5: 1D and 2D NMR spectra of asperorlactone (1).

Author Contributions: Conceptualization, R.O., S.P., and O.T.-S.; methodology, M.F.K., F.A.N., S.P., and A.F.A.; software, A.M.A.-T. and P.L.; validation, S.T.; formal analysis, M.F.K., F.A.N., R.O., and G.C.; investigation, M.F.K., F.A.N., P.L., and G.C.; resources A.S.A. and M.A.W.; writing-original draft preparation M.F.K., F.A.N., and O.T.-S.; writing-review and editing A.S.A., M.A.W., and O.T.-S.; funding acquisition M.F.K., M.A.W., and J.-H.S. All authors have read and agreed to the published version of the manuscript.

Funding: This study was funded by the Deanship of Scientific Research, King Saud University, through the Vice Deanship of Scientific Research Chairs.

Institutional Review Board Statement: In this study, only zebrafish embryos were used which aged less than 5 days post fertilization, and hence, as reported in Reprod. Toxicol. 2012, 33, 128132, doi:10.1016/j.reprotox.2011.06.121, they are exempted to take the ethical approval from ethical committee for the use and care of laboratory animals.

Informed Consent Statement: Not applicable.

Data Availability Statement: The data presented in this study are available in the article and Supplementary Material.

Conflicts of Interest: The authors declare no conflict of interest. 


\section{References}

1. Montaser, R.; Luesch, H. Marine natural products: A new wave of drugs? Future Med. Chem. 2011, 3, 1475-1489. [CrossRef]

2. Carroll, A.R.; Copp, B.R.; Davis, R.A.; Keyzers, R.A.; Prinsep, M.R. Marine natural products. Nat. Prod. Rep. $2019,36,122-173$. [CrossRef]

3. Available online: https://www.marinepharmacology.org (accessed on 25 May 2021).

4. White, K.M.; Rosales, R.; Yildiz, S.; Kehrer, T.; Miorin, L.; Moreno, E.; Jangra, S.; Uccellini, M.B.; Rathnasinghe, R.; Coughlan, L.; et al. Plitidepsin has potent preclinical efficacy against SARS-CoV-2 by targeting the host protein eEF1A. Science 2021, 371, 926-931. [CrossRef] [PubMed]

5. Taglialatela-Scafati, O. New hopes for drugs against COVID-19 come from the sea. Mar. Drugs 2021, 19, 104. [CrossRef] [PubMed]

6. Bugni, T.S.; Ireland, C.M. Marine-derived fungi: A chemically and biologically diverse group of microorganisms. Nat. Prod. Rep. 2004, 21, 143-163. [CrossRef] [PubMed]

7. Gomes, N.G.M.; Lefranc, F.; Kijjoa, A.; Kiss, R. Can some marine-derived fungal metabolites become actual anticancer agents? Mar. Drugs 2015, 13, 3950-3991. [CrossRef]

8. Yoon, J.; Kikuma, T.; Maruyama, J.; Kitamoto, K. Enhanced production of bovine chymosin by autophagy deficiency in the filamentous fungus Aspergillus oryzae. PLoS ONE 2013, 8, e62512. [CrossRef] [PubMed]

9. Singh, B.K.; Park, S.H.; Lee, H.B.; Goo, Y.A.; Kim, H.S.; Cho, S.H.; Lee, J.H.; Ahn, G.W.; Kim, J.P.; Kang, S.M.; et al. Kojic acid peptide: A new compound with anti-tyrosinase potential. Ann. Dermatol. 2016, 28, 555-561. [CrossRef]

10. Orfali, R.; Perveen, S.; Al-Taweel, A.; Ahmed, A.F.; Majrashi, N.; Alluhay, K.; Khan, A.; Luciano, P.; Taglialatela-Scafati, O. Penipyranicins A-C, antibacterial methylpyran polyketides from a hydrothermal spring sediment Penicillium sp. J. Nat. Prod. 2020, 83, 3591-3597. [CrossRef]

11. Orfali, R.; Ebrahim, W.; Perveen, S.; Mejrashi, M.; Alluhayb, K.; Ebada, S.S. Cytotoxic Secondary Metabolites from MangroveRhizosphere-Associated Fungus Emericella sp. Strain SWR1718. J. King Saud Univ. Sci. 2020, 32, 2656-2661. [CrossRef]

12. Orfali, R.; Perveen, S. Secondary metabolites from the Aspergillus sp. in the rhizosphere soil of Phoenix dactylifera (Palm tree). BMC Chem. 2019, 13, 103. [CrossRef]

13. Orfali, R.; Perveen, S. New bioactive metabolites from the thermophilic fungus Penicillium sp. isolated from Ghamiqa hot spring in Saudi Arabia. J. Chem. 2019, 7162948. [CrossRef]

14. Bhusnure, O.; Mane, J.; Gholve, S.; Thonte, S.; Giram, P.S.; Sangshetti, J. Drug target screening and its validation by zebrafish as a novel tool. Pharm. Anal. Acta 2015, 6, 1-9. [CrossRef]

15. MacRae, C.A.; Peterson, R.T. Zebrafish as tools for drug discovery. Nat. Rev. Drug Discov. 2015, 14, 721-731. [CrossRef] [PubMed]

16. Yoganantharjah, P.; Gibert, Y. The use of the zebrafish model to aid in drug discovery and target validation. Curr. Top. Med. Chem. 2017, 17, 2041-2055. [CrossRef] [PubMed]

17. Suzuki, S.; Murayama, T.; Shiono, Y. Echinolactones C and D: Two illudalane sesquiterpenoids isolated from the cultured mycelia of the fungus Echinodontium japonicum. Z. Naturforsch. 2006, 61, 1295-1298. [CrossRef]

18. Lin, A.; Lu, X.; Fang, Y.; Zhu, T.; Gu, Q.; Zhu, W. Two new 5-hydroxy-2-pyrone derivatives isolated from a marine-derived fungus Aspergillus flavus. J. Antibiot. 2008, 61, 245-249. [CrossRef]

19. Kokubun, T.; Scott-Brown, A.; Kite, G.C.; Simmonds, M.S.J. Protoilludane, illudane, illudalane, and norilludane sesquiterpenoids from Granulobasidium vellereum. J. Nat. Prod. 2016, 79, 1698-1701. [CrossRef] [PubMed]

20. Happi, G.M.; Kouam, S.F.; Talontsi, F.M.; Nkenfou, C.N.; Longo, F.; Zuhlke, S.; Douanla-Meli, C.; Spiteller, M. A new dimeric naphtho- $\gamma$-pyrone from an endophytic fungus Aspergillus niger AKRN associated with the roots of Entandrophragma congoënse collected in Cameroon. Z. Naturforsch. 2015, 70, 625-630. [CrossRef]

21. Ebrahim, W.; El-Neketi, M.; Lewald, L.I.; Orfali, R.; Lin, W.; Rehberg, N.; Kalscheuer, R.; Daletos, G.; Proksch, P. Metabolites from the fungal endophyte Aspergillus austroafricanus in axenic culture and in fungal-bacterial mixed cultures. J. Nat. Prod. 2016, 79, 914-922. [CrossRef] [PubMed]

22. Ohtani, I.; Kusumi, T.; Kashman, Y.; Kakisawa, H. High-field FT NMR application of Mosher's method. The absolute configurations of marine terpenoids. J. Am. Chem. Soc. 1991, 113, 4092-4096. [CrossRef]

23. Morisaki, N.; Furukawa, J.; Kobayashi, H.; Iwasaki, S.; Nozoe, S.; Okuda, S. Cyclobutyl cation rearrangements of 6-protoilluden8 $\alpha$-ol, 7-protoilluden-6-ol and related compounds. Chem. Pharm. Bull. 1987, 35, 2678-2685. [CrossRef]

24. McMorris, T.C.; Nair, M.S.R.; Singh, P.; Anchel, M. The structure of illudol. Phytochemistry 1971, 10, 3341-3342. [CrossRef]

25. Nord, C.L.; Menkis, A.; Broberg, A. Cytotoxic illudalane sesquiterpenes from the wood-decay fungus Granulobasidium vellereum (Ellis \& Cragin) Julich. Molecules 2014, 19, 14195-14203.

26. Lu, J.; Peng, C.Y.; Cheng, S.; Liu, J.Q.; Ma, Q.G.; Shu, J.C. Four new pterosins from Pteris cretica and their cytotoxic activities. Molecules 2019, 24, 2767. [CrossRef] [PubMed]

27. Kjer, J.; Debbab, A.; Aly, A.; Proksch, P. Methods for isolation of marine-derived endophytic fungi and their bioactive secondary products. Nat. Protoc. 2010, 5, 479-490. [CrossRef] [PubMed]

28. Finney, D.J. Probit Analysis: A Statistical Treatment of the Sigmoid Response Curve; Cambridge University Press: Cambridge, UK, 1952. 